\title{
Indigenous Scheming and Manufacturing of a Laboratory Scale Heat Treatment Furnace - Technical Report
}

\author{
M. Wahaj ${ }^{1}$, M. Asim ${ }^{1}$, Owais A. W. ${ }^{1}$, Waqas A. W. ${ }^{2}$, S. Anwar ul Hasson ${ }^{{ }^{*}}$ \\ ${ }^{1}$ Karachi Institute of Power Engineering (KINPOE), Hawksbay Road, Karachi, Pakistan \\ ${ }^{2}$ University of Karachi, Karachi-75270, Pakistan \\ *Corresponding author: anwar.ul.hasson@paec.gov.pk
}

Received: July 30,2016 Revised:Aug. 8, 2016 Accepted: Aug. 20, 2016

\begin{abstract}
In order to contribute in the research activities related to heat treatment of metals and other engineering materials, a laboratory scale heat treatment furnace is essentially required. Among several other types of furnaces, electric heat treatment furnace is said to be most useful. It is provided with a programmable controller which precisely controls heating rate, soaking time and cooling rate. The controller also helps in keeping the heat treatment safe by emergency turnoff facility. This manuscript reports the indigenous designing and development of electrical heat treatment furnace, which not only provides enormous learning to fresh graduates but also saved a handsome amount, which could have spent in purchasing same article from commercial market. In this paper, the sequential procedure of furnace designing and development is being shared with the engineering community so that the researchers of under developed countries may save their esteemed educational and research funds.
\end{abstract}

Keywords: Furnace, Heat treatment, Fabrication, Manufacturing

\section{Introduction}

The heat treatment is used to modify the physical and chemical properties of metals, alloys and other engineering materials. It is a set of processes carried out in an inert or reactive environment, i.e. helium, argon, nitrogen, carbon monoxide or carbon dioxide etc., at different temperatures, soaking time, heating and cooling rates. By heat treatment, the microstructures of materials are modified, the resulting phase transformation influences mechanical properties like strength, ductility, toughness, hardness and wear resistance. In simple words, heat treating is used to soften a part that is too hard, harden a part that is not hard enough, put hard skin on parts that are soft and make selective property changes within parts.

\subsection{Heat Treatment Processes}

Universally known heat treatment processes have been presented in Table. 1 [5]. 
Table 1. Heat Treatment Processes [5]

\begin{tabular}{ccc}
\hline \hline S. No. & Heat Treatment & Types \\
1 & Annealing & Full Annealing, Stress Relief Annealing, Sphereodizing \\
2 & Normalizing & Normalizing \\
3 & Hardening \& Tempering & Quenching, Tempering, Austenitizing. \\
4 & Case Hardening & Carburizing, Nitriding, Cyaniding, Flame Hardening \\
\hline
\end{tabular}

Annealing is a heat treatment process that consists of heating to and holding at a suitable temperature followed by cooling at a suitable rate. It is used primarily to soften metallic materials, but also to produce desired changes in other properties or in microstructure. Two types of annealing are stress relief annealing and full annealing. The former is used to relieve stresses, whereas the later imparts softness.

In normalizing, the ferrous alloy are heated up to 28 to $56^{\circ} \mathrm{C}$ above their transformation temperatures and then cooled in still air to at least some temperature well below their transformation temperature range.

Austenite phase is formed by the heat treatment process called austenitizing, by heating a ferrous alloy above transformation range.

Hardening imparts strength and hardness to alloys by heating up to a certain temperature and cooling it rapidly. Steel is heated and held there until its carbon is dissolved, and then cooled rapidly, the carbon does not get sufficient time to escape and get dissipated in the lattice structure. This helps in locking the dislocation movements when stresses are applied. Quenching is performed to cool hot metal rapidly by immersing it in brine (salt water), water, oil, molten salt, air or gas. Selection of a quenching medium depends largely on the hardening ability of material and mass of material being treated [4].

Tempering consists of reheating the austenitized and quench hardened steel or iron to some preselected temperature that is below the lower transformation temperature (generally below $705^{\circ} \mathrm{C}$ ). It offers a mean of obtaining various combinations of mechanical properties

Carburizing, nitriding and carbonitriding are case hardening processes in which a ferrous material is heated above the transformation temperature in a gaseous atmosphere of such composition as to cause absorption of carbon, nitrogen of simultaneous absorption of carbon and nitrogen on surface by diffusion creating a concentration gradient. Temperatures used for these processes are generally in range of $900^{\circ} \mathrm{C}-1040^{\circ} \mathrm{C}$. Process is completed by cooling at a rate that produces the desired properties in the work piece. [4]

The purpose of heat treatment is to increase service life of a product by improving its mechanical properties like strength, hardness, ductility, toughness and fatigue strength etc. the machinability and formability of metals and alloys are also enhanced by heat treatment [1].

\subsection{Commonly Heat Treated Metals and Alloys}

Because of extensive utilization, ferrous metals and alloys such as carbon steel, stainless steel, cast irons and tool steel are very frequently subjected to heat treatment. The heat treatment of some 
nonferrous metals and their alloys such as aluminum, copper, brass and titanium etc. is also done to enhance properties.

\subsection{Heat Treatment Furnaces}

All the heat treatment processes are carried out in highly sophisticated furnaces. Furnace ideally should heat as much of material as possible to a uniform temperature with the least possible fuel and labor. Furnaces are classifies according to the type of fuel utilized, mode of operation and mode of heat transfer, see Table II.

Table 2. Classification of Heat Treatment Furnaces [8]

\begin{tabular}{ccc}
\hline \hline S. No. & Classification Method & Types \\
1 & Type of Fuel & Oil, Gas, Coal, Electricity (Resistance Heating) \\
2 & Mode of Heat Transfer & Convection, Radiation \\
3 & Mode of Operation & Continuous, Batch \\
\hline
\end{tabular}

A furnace may utilize oil, gas, coal or electricity as a fuel, it may transfer heat by convection or by radiation. The heat treatment may be performed in batches or in continuous operation by using batch and continuous furnace respectively. A batch furnace is selected for individual or small series production. Materials are manually charged and discharged in a batch furnace. A continuous furnace operates in uninterrupted cycle and the work pieces move through it. Consequently, continuous furnace is readily adaptable to automation and thus are used for high volume work. Another advantage of continuous furnaces is the precise repetition of time-temperature cycle, which is a function of rate of travel through the various furnace zones [8]. In addition to heat treatment, several furnaces are used for sintering or various materials as well [7].

Electric heat treatment furnace provides the facility to control process parameter very precisely, therefor it is of great interest and importance. Keeping this in view, the electric heat treatment furnace has been developed and sequential procedure is being presented in this paper. This systematic approach, will guide the engineers and they will be able to develop heat treatment furnace indigenously at a cost much lower than the prices of furnaces available in commercial market.

\section{Designing of Furnace}

The model of electric heat treatment furnace was generated by using Solid edge V-16.3D. Models and orthographic projections were generated according to the finalized furnace size, Fig. 1 and 2. The size is decided keeping in view the sample size which is to be heat treated in furnace and the thickness of insulation.

At first, solid body and legs of heat treatment furnace was created, as presented in Fig. 1(a). After this cutouts for charging door and control panel were created, Fig. 1(b). From charging door the material is charged in the furnace and control penal consists of electric switches, alarms, controller etc. The internal chamber were designed with the provision of insulation and heating elements inside it. The heating chamber is insulated either by refractory bricks or glass wool. Heating coils are embedded in insulation. Then charging door and door of control panel were designed at the face 
of charging door Fig. 1(c). In succeeding steps the provisions for selector switches, temperature controller, penal buzzer, vent port, peep hole and indication lights were created on the control panel, finally heating chamber was incorporated with heating element and blower Fig. 1(e and f).

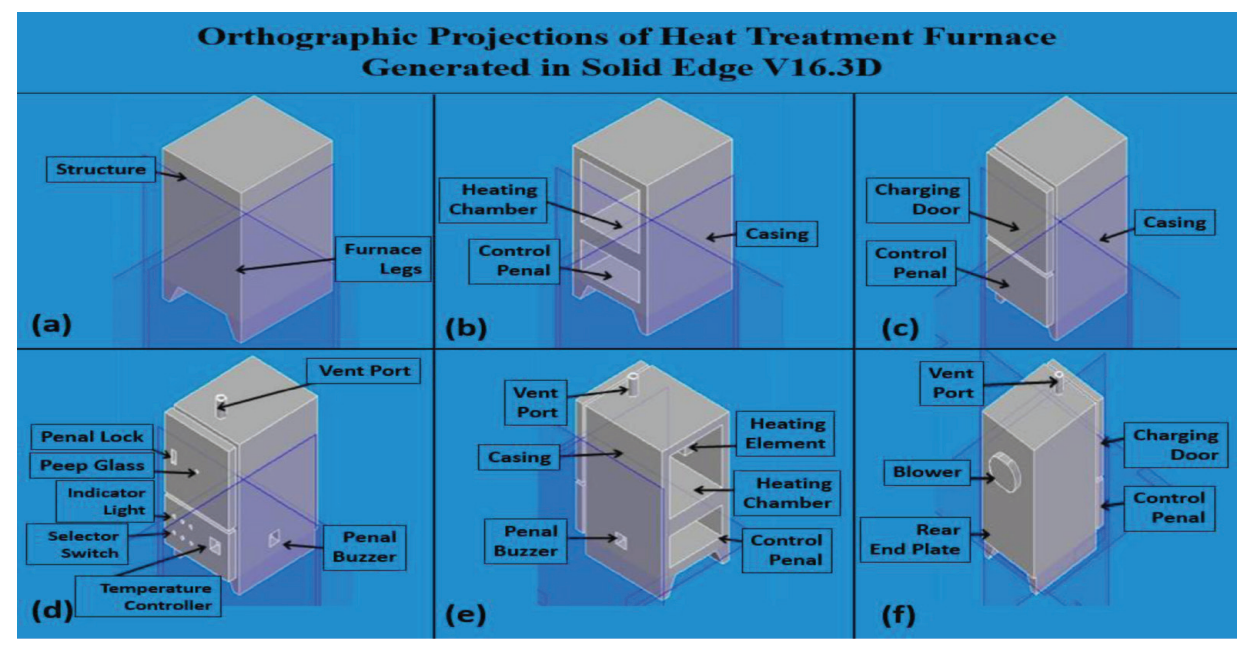

Fig. 1: Orthographic projections of heat treatment furnace

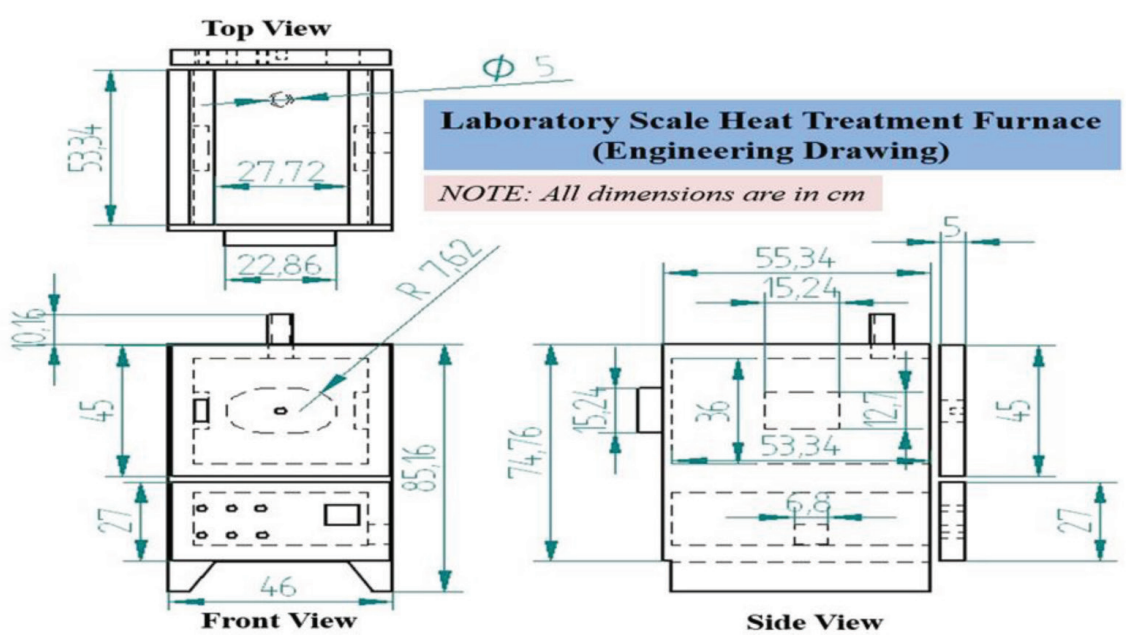

Fig. 2: Engineering drawing with dimensions of laboratory scale heat treatment furnace

\section{Components}

Components of electric heat treatment furnace are divided into two categories: electrical and mechanical components. Former includes thermocouple, temperature controller, heating element, indicator lights, selector switch and circuit breaker, whereas later includes Refractory/Insulation, casing of furnace, peep glass, vent port, hinges, blowers and panel lock. The electrical components have been procured from local market as in Fig. 3, with the specifications mentioned in Table III. 


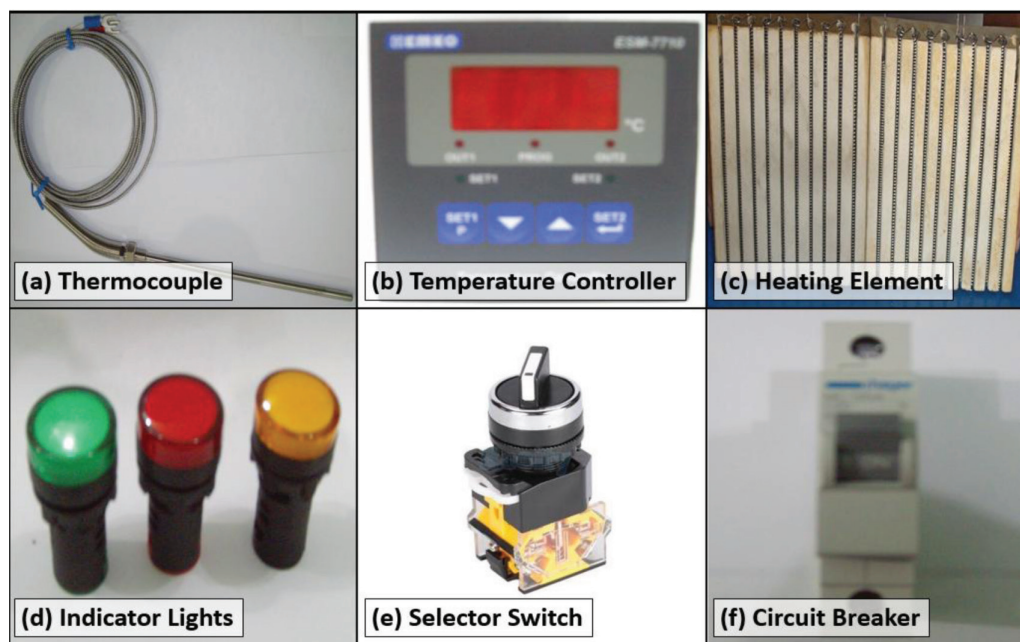

Fig. 3: Electrical components of a lab scale heat treatment furnace

Table 3. Specifications of the Electrical Components

\begin{tabular}{|c|c|c|}
\hline \multirow{2}{*}{$\begin{array}{l}\text { Components. } \\
\text { Thermocouple }\end{array}$} & \multicolumn{2}{|c|}{ Specifications } \\
\hline & Type & K type \\
\hline & Melting Point & $1350^{\circ} \mathrm{C}$ \\
\hline & Maximum Temperature & $1260^{\circ} \mathrm{C}$ \\
\hline & Wire gage Size & 8 Gage $(4.06 \mathrm{~mm})$ \\
\hline & Standard Tolerance & $+2.2{ }^{\circ} \mathrm{C}$ \\
\hline \multirow{8}{*}{$\begin{array}{l}\text { Temperature } \\
\text { Controller }\end{array}$} & Dimensions & $72 \mathrm{mmx} 72 \mathrm{mmx} 95.5 \mathrm{~mm}$ \\
\hline & Supply Voltage And Power & $230 \mathrm{~V}, 3 \mathrm{VA}$ \\
\hline & Temperature Inputs & NTC, PTC, TC, RTD \\
\hline & Thermocouple Input Types & $\mathrm{J}, \mathrm{K}$ \\
\hline & Weight & Approximately $0.21 \mathrm{Kg}$ \\
\hline & Accuracy & $\pm 1 \%$ of full scale for thermocouple \\
\hline & Control Form & $\mathrm{ON} / \mathrm{OFF}$ \\
\hline & Display & $14 \mathrm{~mm}$ Red 3 digits LED display \\
\hline \multirow[t]{6}{*}{ Heating Element } & Materials & Ni80-Cr20 \\
\hline & Maximum temperature & $1150{ }^{\circ} \mathrm{C}$ \\
\hline & Approx. Melting Point & $1400^{\circ} \mathrm{C}$ \\
\hline & Type & Embedded/Supported \\
\hline & Length & 6 inches \\
\hline & Power & 2 element sets of $1000 \mathrm{~W}$ each \\
\hline \multirow[t]{3}{*}{ Indicator Lights } & Type & $\mathrm{AD} 22-22 \mathrm{DS} / \mathrm{R}$ \\
\hline & Conventional heating current & $10 \mathrm{~A}$ \\
\hline & Rated insulation Voltage & AC600V(50Hz-60Hz) \\
\hline
\end{tabular}




\begin{tabular}{ccc} 
& Operational temperature & $25 \sim 70{ }^{\circ} \mathrm{C}$ \\
& Power-frequency withstand voltage & $2500 \mathrm{~V} \mathrm{AC}$ \\
& Contact resistance & $\leq 50 \mathrm{~m} \Omega$ \\
& Color & Green, red, yellow \\
\hline Selector Switch & Model & Keepow LA22B \\
& Standard & IEC 33 \\
& Rated Voltage & UI 660V \\
& Current & $10 \mathrm{~A}$ \\
\hline Circuit Breaker & Current & C20 \\
& Model & Id No 0010 2335 2176 4643
\end{tabular}

Thermocouple have been used to measure the temperature on the basis of voltage generated because of the temperature difference between measuring and reference junction. The properties of standard thermocouple and the relationship between thermocouple temperature and wire gauges are shown in Table IV [3] and Table V [2] respectively. The temperature controller is used to maintain the temperature by comparing actual temperature with its set point and producing an output signal. While selecting a controller, the type of input sensor (thermocouple, RTD, card, and temperature range), placement of sensor, control algorithm needed (on/off, proportional, PID), type of output hardware required (electromechanical relay, SSR, analog output signal) are considered. The type of input sensor will depend on the temperature range required, the resolution and accuracy of the measurement required, and how and where the sensor is to be mounted. Before selecting the location for the sensing element, it is determined that whether the heat demand will be predominantly steady or variable. If the heat demand is relatively steady, placement of the sensing element near the heat source will hold the temperature change at the work to a minimum. On the other hand, placing the sensing element near the work, when heat demand is variable, will enable it to more quickly sense a change in heat requirements [6]. When a current flows through a conductor of resistance $(\mathrm{R})$, heat is produced and there is temperature rise of conductors in electrical circuits [9]. The heating element should have melting point greater than furnace temperature, it should not react with the atmosphere of the furnace and it should be resistant to thermal and mechanical shock.

Indicator lights, also referred to as pilot lights, provide a visual indication of a circuit's operating condition, for example, on, off, or alarm. Indicator lights are available in local market, with a variety of lens colors to allow for a quick visual indication of machine or process status. Selector switches are installed to select any of the operation modes of the furnace. The circuit breaker is installed to protect an electrical circuit from damage caused by overload or short circuit. Its basic function is to detect a fault condition and interrupt current flow. Unlike a fuse, which operates once and then must be replaced, a circuit breaker can be reset either manually or automatically to resume normal operation [10].

Table 4. Properties of Standard Thermocouples [3].

\begin{tabular}{llll}
\hline Type & Base Composition & Melting point $\left({ }^{\circ} \mathrm{C}\right)$ & Maximum Temperature $\left({ }^{\circ} \mathrm{C}\right)$ \\
\hline $\mathrm{J}$ & $\mathrm{Fe}$ & 1450 & 760 \\
& $44 \mathrm{Ni}-55 \mathrm{Cu}$ & 1210 & \\
\hline
\end{tabular}




\begin{tabular}{llll}
\hline \multirow{2}{*}{$\mathrm{K}$} & $90 \mathrm{Ni}-9 \mathrm{Cr}$ & 1350 & \multirow{2}{*}{1260} \\
\hline \multirow{2}{*}{$\mathrm{N}$} & $94 \mathrm{Ni}-\mathrm{Al}, \mathrm{Mn}, \mathrm{Fe}, \mathrm{Si}$ & 1400 & \multirow{2}{*}{1260} \\
\hline \multirow{2}{*}{$\mathrm{T}$} & $95 \mathrm{Ni}-14 \mathrm{Cr}-1.4 \mathrm{Si}$ & 1410 & \\
\hline \multirow{2}{*}{$\mathrm{E}$} & OHFCCu & 1400 & \multirow{2}{*}{370} \\
& $44 \mathrm{Ni}-55 \mathrm{Cu}$ & 1083 & \\
\hline
\end{tabular}

Table 5. Relationship between wire gauges and thermocouple temperatures [2]

\begin{tabular}{cccccc}
\hline Type & $\begin{array}{c}8 \text { Gauge } \\
(4.06 \mathrm{~mm})\end{array}$ & $\begin{array}{c}16 \text { Gauge } \\
(1.63 \mathrm{~mm})\end{array}$ & $\begin{array}{c}20 \text { Gauge } \\
(0.91 \mathrm{~mm})\end{array}$ & $\begin{array}{c}24 \text { Gauge } \\
(0.56 \mathrm{~mm})\end{array}$ & $\begin{array}{c}28 \text { Gauge } \\
(038 \mathrm{~mm})\end{array}$ \\
\hline $\mathrm{J}$ & $760^{\circ} \mathrm{C}$ & $560{ }^{\circ} \mathrm{C}$ & $480{ }^{\circ} \mathrm{C}$ & $480{ }^{\circ} \mathrm{C}$ & $480{ }^{\circ} \mathrm{C}$ \\
$\mathrm{K}$ & $1260^{\circ} \mathrm{C}$ & $1000^{\circ} \mathrm{C}$ & $980^{\circ} \mathrm{C}$ & $870{ }^{\circ} \mathrm{C}$ & $820^{\circ} \mathrm{C}$ \\
$\mathrm{T}$ & $400^{\circ} \mathrm{C}$ & $370^{\circ} \mathrm{C}$ & $260^{\circ} \mathrm{C}$ & $200{ }^{\circ} \mathrm{C}$ & $200{ }^{\circ} \mathrm{C}$ \\
$\mathrm{N}$ & $1260^{\circ} \mathrm{C}$ & $1000^{\circ} \mathrm{C}$ & $980^{\circ} \mathrm{C}$ & $870{ }^{\circ} \mathrm{C}$ & $820^{\circ} \mathrm{C}$ \\
$\mathrm{E}$ & $870{ }^{\circ} \mathrm{C}$ & $620^{\circ} \mathrm{C}$ & $540{ }^{\circ} \mathrm{C}$ & $430{ }^{\circ} \mathrm{C}$ & $400{ }^{\circ} \mathrm{C}$ \\
\hline
\end{tabular}

The mechanical structure of the furnace have been developed with mild steel sheet of 18 guage, ceramic wool, penal lock, exhaust fan, peep glass and stainless steel wire, see Fig. 4.

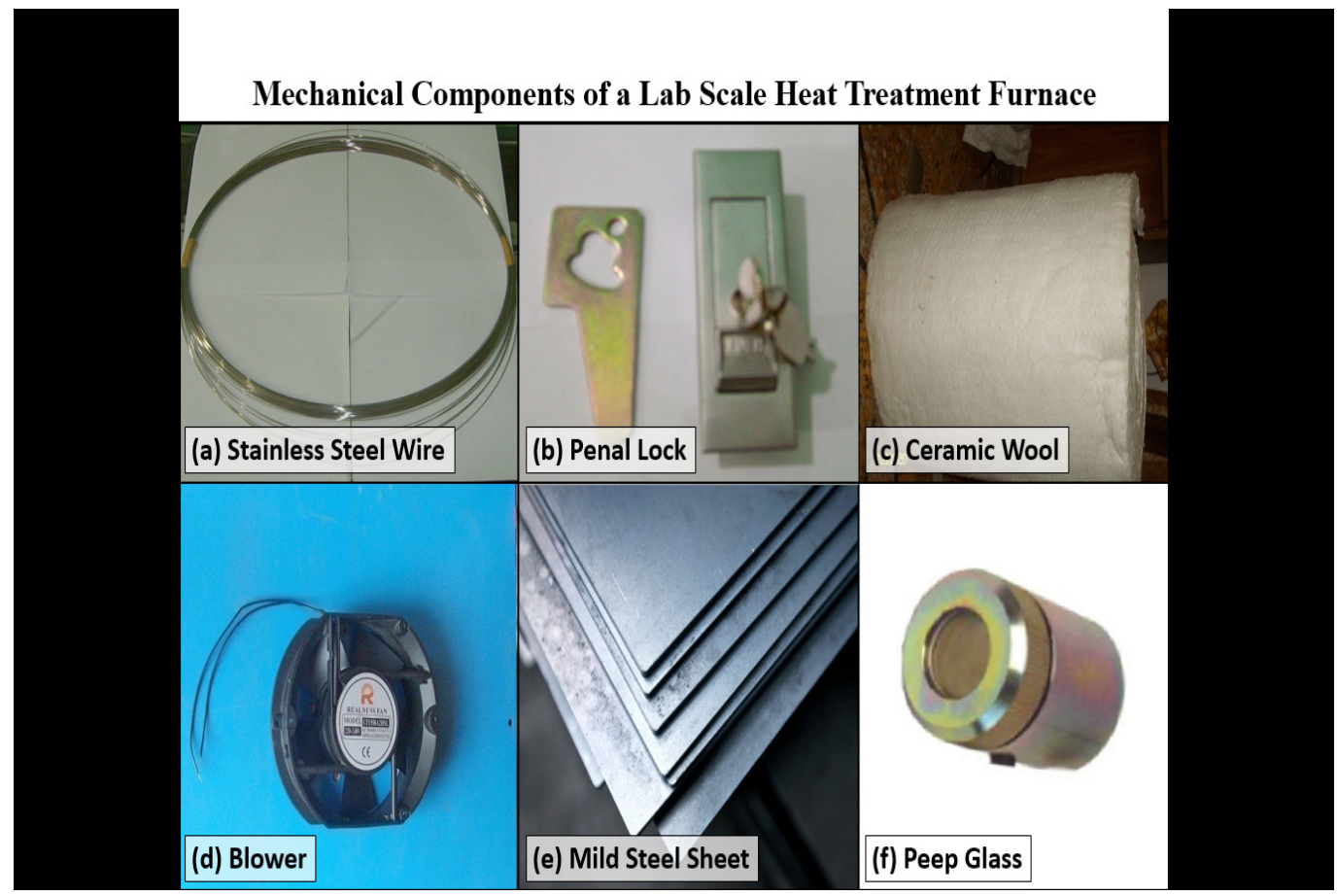

Fig. 4: Mechanical components of a lab scale heat treatment furnace 


\section{Fabrication}

The fabrication of the furnace have been carried out by step by step construction from simple mild steel structure to final product through the installation of electrical and mechanical components. In order to fabricate the furnace casing and charging door, a flat mild steel sheet with thickness of 18 gauge have been used, for its appreciable ductility, strength, toughness and formability. During casing fabrication, the sheet undergone several bending, shearing and arc welding operation.

Selector switches, indicator lights, buzzer and temperature controller serve an important purpose in heat treatment furnace. Selector switches are used to link control panel with different electrical components, indication lights are used to indicate the particular selector switch in service, controller controls the temperature and maintain it at any required set point, the buzzer indicate end of any operation such as heating, soaking or cooling. For placing these important electrical components, a control panel, having provision all these electrical components were required, which was fabricated via drilling and shearing and bending of mild steel sheet. A hole at the center of charging door was produced for peep glass assembly. A vent hole was produced at the top, and the holes for supplying air via blower, whenever required, were produce at the rear end plate. The burs produced while fabricating process were being removed by grinding.

The furnace casing, charging door and control penal were fabricated separately, then all there were joined together via barrel hinges, nuts and bolts

\section{A. Installation of Electrical Components}

The temperature controller, switches and lights have been fixed at the front of control panel, whereas panel buzzer have been fixed at the right side of casing. Square shaped cutout were created for panel buzzer and temperature controller. Circuit breaker and contactor have been placed on a reserved plate at the back side of the control penal.

\section{B. Installation of Mechanical Components}

During heat treatment process, the furnace door is kept locked. For this purpose, a panel lock was installed. The vent port was fixed in the vent hole, at the top of the furnace, with an adjustable canopy so that it could be closed and opened as per requirement of the process. The blower fan was installed at the rear plate with the help of screws. The fan was installed to provide air, in order to accelerate the heat removal rate, whenever desired. Ceramic wool, two inches (2") thick, which provides excellent insulation, was used to cover the heating chamber and charging door from inner side. The ceramic wool minimizes the heat losses by retaining heat inside the heating chamber. Two sets of embedded heating elements were installed on both sides of the heating chamber. The heating element were connected to the control circuitry. Heat proof sleeves were used to protect connecting wires from heat. After installing all the components, the furnace was painted to keep the mild steel structure safe from atmospheric corrosion and to make it aesthetically attractive. The different stages of fabricating process has been shown via snapshots, see Fig. 5. 


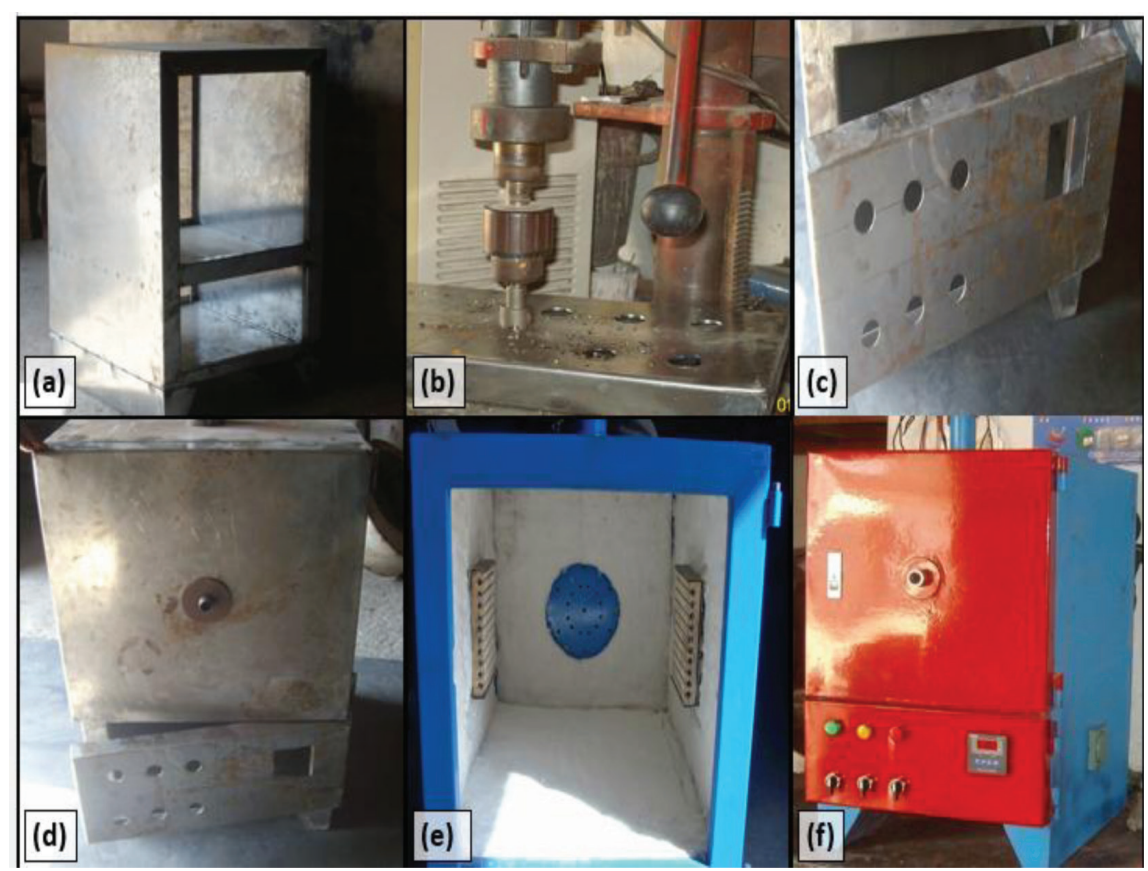

Fig. 5: Snapshots at different stages of fabricating process

\section{Commissioning}

For commissioning and starting heat treatment operation, an alloy steel of grade AISI-4140 was taken. The chemical composition is shown in Table IV.

Table 6. Composition of Alloy Steel AISI-4140

\begin{tabular}{|c|c|c|c|c|c|c|c|}
\hline Alloying Element & $\mathrm{C}$ & $\mathrm{Mn}$ & $\mathrm{P}$ & $\mathrm{S}$ & $\mathrm{Si}$ & $\mathrm{Cr}$ & $\mathrm{Mo}$ \\
\hline Percentage & $0.38-0.43$ & $0.75-1.00$ & 0.035 & 0.040 & $0.15-0.35$ & $\begin{array}{c}0.15- \\
0.25\end{array}$ & $\begin{array}{c}0.15- \\
0.25\end{array}$ \\
\hline
\end{tabular}

Steel was heated to $850^{\circ} \mathrm{C}$ to form austenite, then it was cooled rapidly by oil quenching. Rapid cooling prevents $\mathrm{C}$ diffusion and causes martensite transformation to take place. During this transformation $\mathrm{C}$ atoms traps inside the crystal structure and martensite phase forms, see Fig. 6.

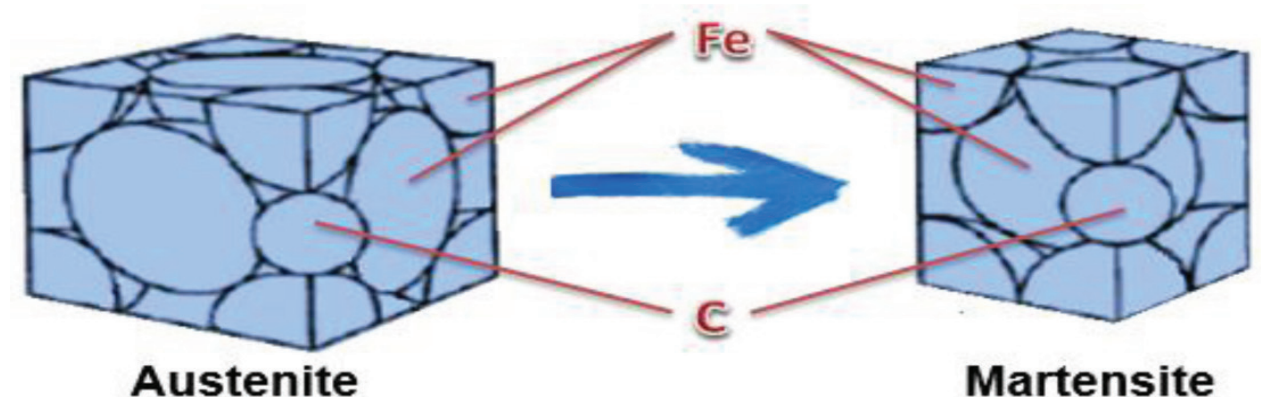

Fig. 6: Martensite transformation 
In order to examine the microstructure of the heat treated sample, the metallographic examination was done by following standard procedure. Rough and fine grinding of the sample was done by using sand paper having diameter size of particles ranges 115-162um and 15.3-23.0 um respectively. Polishing was done by rubbing the specimen against a nylon cloth after applying diamond paste. Then the specimen was etched by using NITAL and then washed by acetone. Then the specimen was examined under metallurgical microscope.

The resulting steel showed needle shaped grains in micrograph, see Fig. 7. This structure is called martensitic which is extremely hard, that it won't scratch, but very brittle, so it became easily breakable under stress. Martensite is a metastable phase it is usually tempered to convert martensite partially into ferrite and cementite.

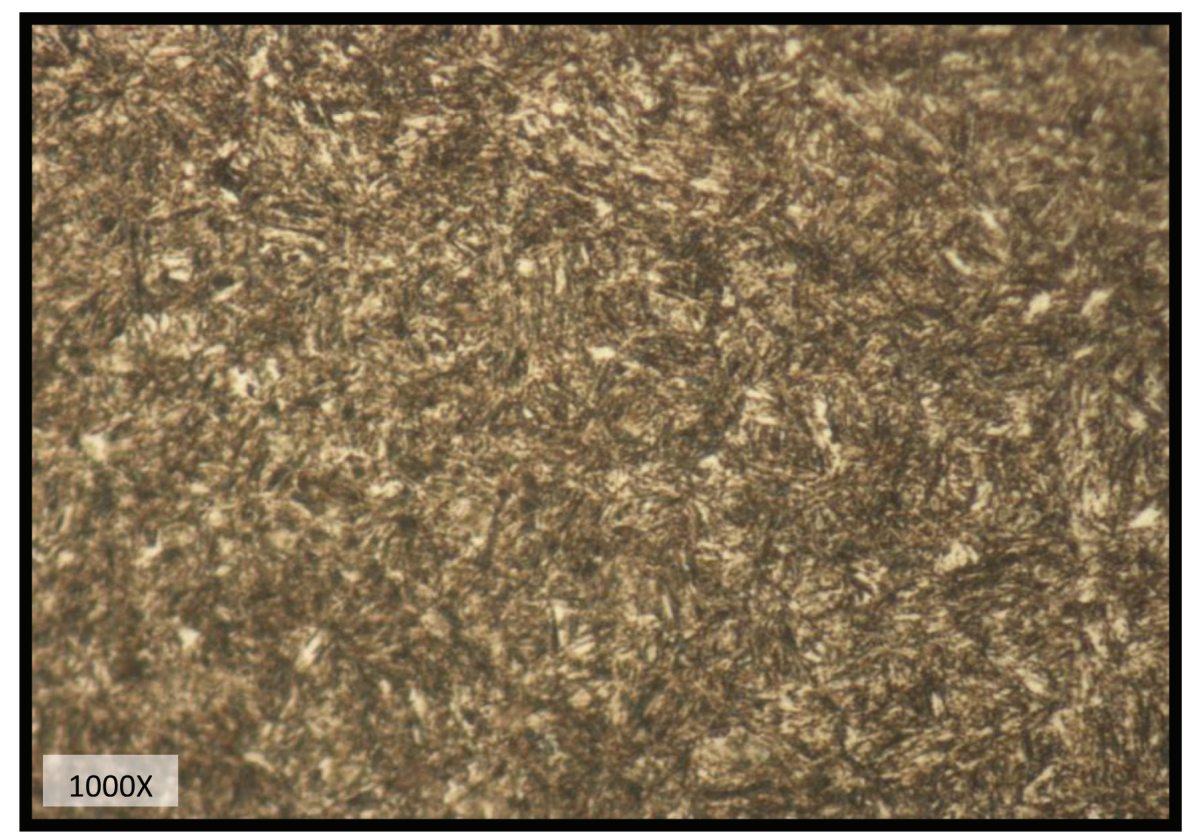

Fig. 7: Micrograph of Nital etched specimen of AISI-4140 at $1000 \mathrm{x}$

The micrograph of heat treated specimen showed results as expected by the applied heat treated cycle. The flawless results of heat treatment suggest that the furnace operates properly.

\section{Conclusion}

The designing and development of electric heat treatment furnace provided learning not only about designing, manufacturing and experimentation to graduate students. It also made the young engineers deal with project planning, problem solving and engineering economics. This noncommercial project equipped the lab with a highly useful and economic experimental facility i.e. a heat treatment furnace while giving researchers a practical experience of manufacturing before going into the field work. The idea was successful to execute an applied research project for technical and economic benefits. 


\section{Acknowledgement}

The authors are thankful to all teachers and fellows who guided and helped in carrying out this non-commercial academic project.

\section{References}

[1] Bo L, Yimin G, Junhong J, Minmin H, Hongjian G and Wenzhen W (2016), Influence of heat treatments on the microstructure as well as mechanical and tribological properties of NiCrAlYMo-Ag coatings. Journal of Alloys and Compounds, 686: 503-510.

[2] Carlson RJ and Simons CC (1968), Electric resistance heater and method of making, Google Patents. [Online: https://www.google.com/patents/US3404202] (Retrieved on 05.08.2016)

[3] Davis JR (2000), ASM specialty handbook: Nickel, cobalt and alloys. ASM International, ISBN: $987087170685-0$

[4] Feng C and Tahir IK (2008), The effect of quenching medium on the wear behaviour of a Ti6Al-4V alloy, Journal of Materials Science, 43(2) : 788-792. DOI: 10.1007/s10853-007-2298-y.

[5] George ET (2006), Steel Heat Treatment, Metallurgy and Technologies, Second Edition, Taylor \& Francis Group., CRC Press, USA, ISBN-13:978-0-8493-8455-5

[6] Haynes ACR (1971), Temperature controllers, Google Patents. (Retrieved on 05.08.2016) on [Online: https://www.google.com/patents/US3612165].

[7] Owais AW and Ho JR (2016), Tungsten-Based Composite for Nuclear Fusion Applications, Nuclear Materials Performance, Nuclear Materials. InTech Publisher, 139 161, ISBN 978-95351-2448-1.

[8] Rajan TV, Sharma CP and Sharma A (2011), Heat Treatment, Principles and Techniques, Second Edition, PHI Learning Pvt. Ltd., New Delhi-110001.

[9] Rich JR (1961), Resistance heating in the arc cathode spot zone. Journal of Applied Physics, 32 (6) : 1023-1031.

[10] Weedy BM (1972), Electric Power Systems, Second Edition, John Wiley and Sons, London, ISBN 0-471-92445-8, 428-430. 